\title{
CFHRI is a potentially downregulated gene in lung adenocarcinoma
}

\author{
GETING WU ${ }^{1 *}$, YUANLIANG YAN $^{2,3 *}$, XIANG WANG $^{2,3}$, XINXIN REN $^{4}, \mathrm{XI} \mathrm{CHEN}^{2,3}$, \\ SHUANGSHUANG ZENG ${ }^{2,3}$, JIE WEI ${ }^{2,3}$, LONG QIAN $^{2,3}$, XUE YANG $^{2,3}$, CHUNLIN OU $^{1}$, \\ WEI LIN ${ }^{1}$, ZHICHENG GONG ${ }^{2,3}$, JIANHUA ZHOU ${ }^{1}$ and ZHIJIE XU ${ }^{1,3}$ \\ Departments of ${ }^{1}$ Pathology and ${ }^{2}$ Pharmacy, ${ }^{3}$ Institute for Rational and Safe Medication Practices, \\ National Clinical Research Center for Geriatric Disorders, ${ }^{4}$ Key Laboratory of Molecular Radiation Oncology of \\ Hunan Province, Center for Molecular Medicine, Xiangya Hospital, Central South University, \\ Changsha, Hunan 410008, P.R. China
}

Received February 20, 2019; Accepted August 8, 2019

DOI: $10.3892 / \mathrm{mmr} .2019 .10644$

\begin{abstract}
There is increasing evidence that human complement factor H-related protein $1(C F H R 1)$ plays a crucial role in the development of malignant diseases. However, few studies have identified the roles of CFHRI in the occurrence and prognosis of lung adenocarcinoma (LADC). In the present study, comprehensive bioinformatic analyses of data obtained from the Oncomine platform, UALCAN and Gene Expression Profiling Interactive Analysis (GEPIA) demonstrated that $C F H R I$ expression is significantly reduced in both LADC tissues and cancer cells. The patients presenting with downregulation of CFHR 1 had significantly lower overall survival (OS) and post progression survival (PPS) times. Through analysis of the datasets from Gene Expression Omnibus database, we found that the compound actinomycin D promoted CFHRI expression, further displaying the cytotoxic effect in the LADC cell line A549. In addition, the expression level of $C F H R I$ in the cisplatin-resistant LADC cell line CDDP-R (derived from H460) was also significantly reduced. Our research demonstrated that low levels of $C F H R 1$ are specifically found in LADC samples, and $C F H R I$ could serve as a potential therapeutic target for this subset of lung cancers. Determination of the detailed roles of $C F H R 1$ in LADC biology could provide insightful information for further investigations.
\end{abstract}

Correspondence to: Professor Jianhua Zhou or Dr Zhijie Xu, Department of Pathology, Xiangya Hospital, Central South University, 87 Xiangya Road, Changsha, Hunan 410008, P.R. China E-mail: zhoujh15@163.com

E-mail:xzj1322007@csu.edu.cn

${ }^{*}$ Contributed equally

Key words: CFHR1, lung adenocarcinoma, occurrence, prognosis, therapeutic target

\section{Introduction}

Lung cancer, as is well known, is the most common cause of cancer-related deaths all over the world. As a malignant tumor, lung cancer kills countless patients worldwide $(1,2)$. Every year, 1.8 million individuals are diagnosed with lung cancer, and 1.6 million patients die as a result of the disease. In addition, the incidence rate of lung adenocarcinoma (LADC), the most common histologic subtype of lung cancer, has continued to increase in men and women (3). However, due to the delay in diagnosis, the treatment results for LADC remain unsatisfactory; 5-year survival rates vary from 4 to $17 \%$ depending on the stage and on regional differences (4). Moreover, the treatment and prognosis of LADC are still public health issues characterized by no progress in advanced diagnosis and treatment $(1,5,6)$. Therefore, there is an urgent need to discover new molecular biomarkers for the early diagnosis and treatment of LADC.

The human complement factor $\mathrm{H}(\mathrm{CFH})$-related protein (CFHR) family is composed of five members: CFHR1, CFHR2, CFHR3, CFHR4 and CFHR5, and each member of this group can bind to the central complement component $\mathrm{C} 3 \mathrm{~b}$. Mutations, genetic deletions, duplications or rearrangements in the individual $C F H R$ genes are associated with many diseases, including cancer $(7,8)$. Recent research shows that $\mathrm{CFH}$-related genes (CFHR1-5) are associated with age-related macular degeneration (AMD) (9). At the same time, large international genome-wide association studies have shown that deletion of CFHR 1 is associated with a reduced risk of developing $\operatorname{IgA}$ nephropathy (10). Fratelli et al (11) found that the germinal homozygous deletion of the CFHRl gene could act as a promising risk factor for acute myelogenous leukemia. Another report also indicated that $C F H R 1$ was homozygously deleted in the cisplatin-resistance glioma cell lines U251 and CP2 (12). However, few studies have reported the relationship between the CFHR family and LADC, and the influence of CFHRI on the pathological process of LADC remains unexplored.

The aim of the present study was to evaluate the function of $C F H R 1$ and its relationship with clinical treatment and prognosis in human LADC. Our data indicate that $C F H R I$ functions as a potential tumor suppressor in LADC tissues and 
cell lines. Kaplan-Meier analysis suggests that $C F H R I$ is an independent prognostic factor for LADC patients.

\section{Materials and methods}

Data collection and reanalysis using different bioinformatic methods. The expression levels of CFHR1 in LADC tissues and cell lines are evidenced by a variety of bioinformatic network resources (Table S1).

Oncomine, a bioinformatics project that analyzes cancer transcriptome data to make it available to the biomedical research community, contains 65 gene expression datasets (13). UALCAN provides a silicon-based platform for validation of target genes and identification of tumor subpopulation-specific candidate biomarkers (14). GEPIA is a web server for gene expression profiling and interactive analyses in human cancers. It provides several key interactive customization features, such as differential expression analysis, patient survival analysis, and similarity gene detection (15). Through these public bioinformatics platforms, we clearly defined the expression profile of CFHRI in human LADC tissues and cell lines.

Kaplan-Meier plotter is a web-based tool for assessing the impact of 54,675 genes on the survival of 10,461 cancer samples and quickly determining the prognosis of the diseases (16), such as overall survival (OS) and post progressive survival (PPS) (17).

We downloaded the therapeutic transcriptome microarray dataset from the Gene Expression Omnibus (GEO) database under the login numbers GSE6400 (18) and GSE21656 (19). Then, we re-analyzed the original data in these datasets to further understand the impact of $C F H R 1$ expression on the chemotherapy response of LADC patients.

The web resource cBioPortal of cancer genomics provides a desired strategy for the exploration, visualization and analysis of multidimensional cancer genomics data (20). We used it to screen the coexpressed genes of CFHRI in LADC tissues. Protein-protein interaction (PPI) networks of these coexpressed genes were constructed using the STRING database (21). Then, Cytoscape software (version 3.0) was used to perform detailed visualization (22).

Next, we used the web-based Gene SeT AnaLysis Toolkit (WebGestalt) to perform Gene Ontology (GO) enrichment analysis (23). Meanwhile, the Pathview algorithm was used to analyze the relevant KEGG pathways (24).

Statistical analyses. The Student's t-test and the statistical software package SPSS (SPSS12.0, IBM Analytics) were used to analyze the differentially expressed mRNAs between cancer tissues and noncancer tissues. Meanwhile, the relationship between $C F H R 1$ expression and clinicopathological features of LADC patients was analyzed using a Chi-square test. The variants with statistical significance in single-factor analysis were further examined by multiple-factor analysis using the COX regression model. Pearson correlation coefficient was used to evaluate the correlation between genes. If $\mathrm{P} \leq 0.05$, then the result was considered statistically significant.

\section{Results}

CFHR1 is downregulated in LADC tissues. To detect changes in $C F H R 1$ expression between LADC and adjacent nontumor tissues, the expression profiles of $C F H R 1$ were analyzed using three independent bioinformatic databases. First, as shown in Fig. 1A, it was found that CFHRl transcription levels were significantly reduced in tumor tissues based on two microarray datasets from the Oncomine platform $(25,26)$. Furthermore, the downregulation of $C F H R l$ transcription was confirmed in LADC tissues by using the UALCAN tool (Fig. 1B). Finally, to further confirm this result, the expression of CFHRI was re-analyzed in the GEPIA database and the same above-mentioned trend was verified (Fig. 1C). This observation confirmed that CFHRI is downregulated in LADC tissues.

CFHRI as a presumed prognostic factor for adenocarcinoma. To date, almost no literature has reported the relationship between the expression of $C F H R I$ and the clinical prognosis of human LADC. Thus, we conducted a clinical follow-up survey with the most commonly used monitoring indicators, OS and PPS (17,27). By using the Kaplan-Meier plotter platform, it was found that patients with downregulated $C F H R I$ expression had a significantly shorter OS $(\mathrm{P}<0.01)$ (Fig. 2A). Moreover, patients with high levels of CFHRl tended to have a longer PPS, although this difference was not significant (P>0.05) (Fig. 2B). The reasons may be due to the sample size, and future evaluations with larger datasets are warranted. Furthermore, associations between $C F H R 1$ expression and $K R A S$ mutation or $\mathrm{T}$ stage were observed to be statistically significant $(\mathrm{P}=0.013$ and $\mathrm{P}=0.002$, respectively) (Table I). No correlation was observed between $C F H R 1$ expression and sex, age, race, EGFR mutation, EML4-ALK translocation, lymph node metastasis, distant metastasis, pathologic stage, smoking history and Karnofsky performance score (Table I). The multiple-factor analysis using the COX regression model indicated that pathological $\mathrm{T}$ stage was independently associated with $C F H R 1$ transcription levels in LUAD samples (Table II). In summary, decreased $C F H R 1$ expression in patients with LADC is likely to be a valuable prognostic factor.

Role of CFHR1 in the treatment of adenocarcinoma. Next, from the GEO database, we screened two microarray datasets related to chemotherapy to further determine the effect of CFHRI in the treatment of LADC patients. From the data of GSE6400 (18), it was found that treatment with the anticancer agent actinomycin D obviously upregulated the expression of $C F H R 1$, further exerting this anti-proliferative activity in cultured A549 LADC cells $(\mathrm{P}=0.017)$ (Fig. 3A). Meanwhile, data from GSE21656 (19) indicated that the expression of CFHR1 in a cisplatin-resistant LADC cell line (CDDP-R) was significantly downregulated when compared with the parental cell line H460 ( $\mathrm{P}=0.03$ ) (Fig. 3B). These findings showed that changes in CFHRI expression levels may be involved in the therapeutic response to cancer.

Network analysis of coexpressed genes of CFHRl. To further understand the biological function of $C F H R 1$, we performed functional enrichment annotation analysis of its coexpressed genes. We downloaded the coexpressed genes of CFHR 1 from the cBioPortal database and screened 243 coexpressed genes with criteria of $\mathrm{P} \leq 0.05$ and $\mid \mathrm{LogFCl} \geq 0.7$ (Table SII). Then, the PPI network of 243 differentially coexpressed genes was 
A

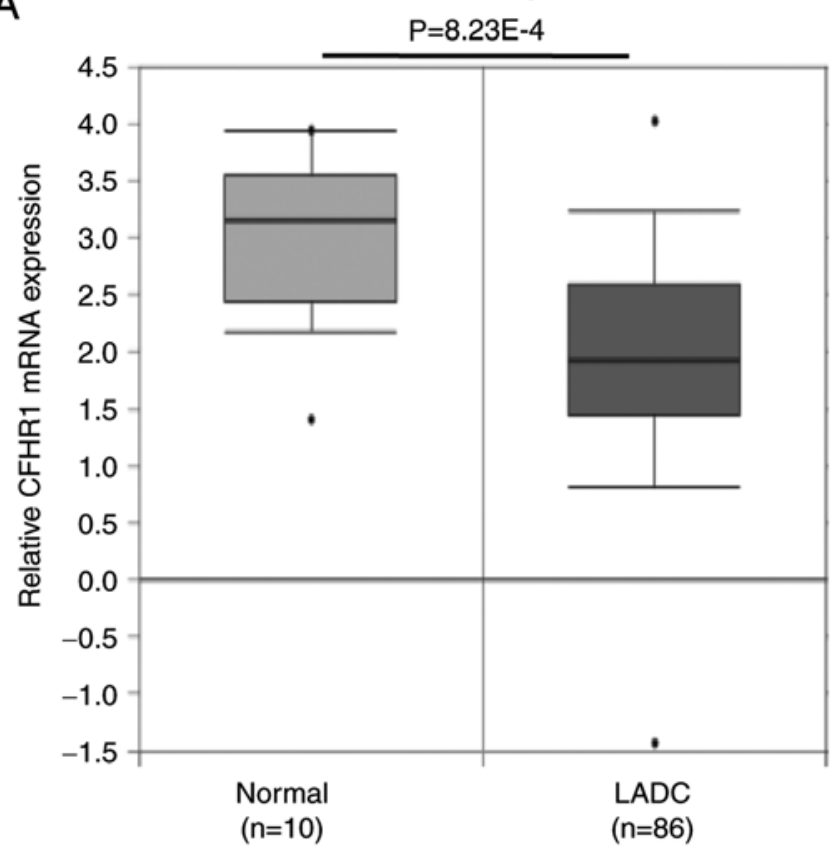

B

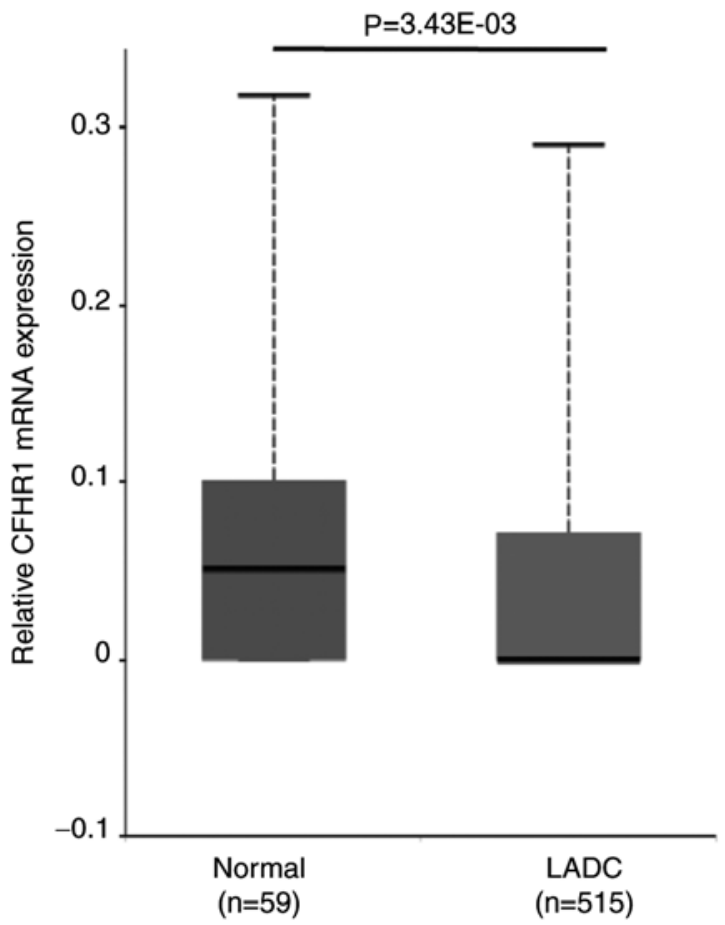

Bhattacharjee lung

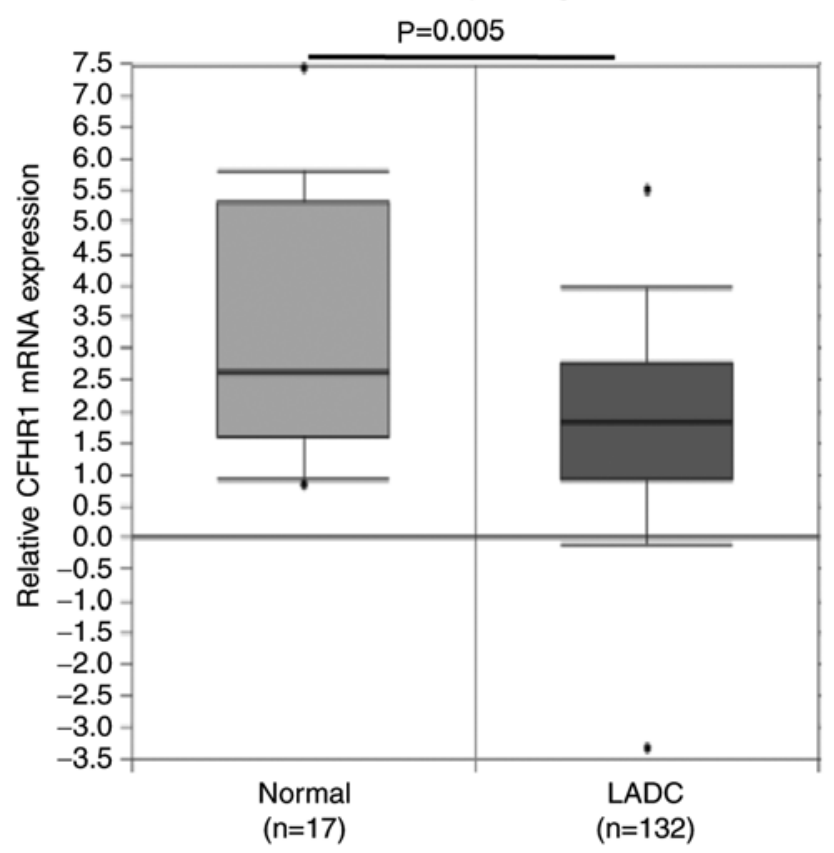

C

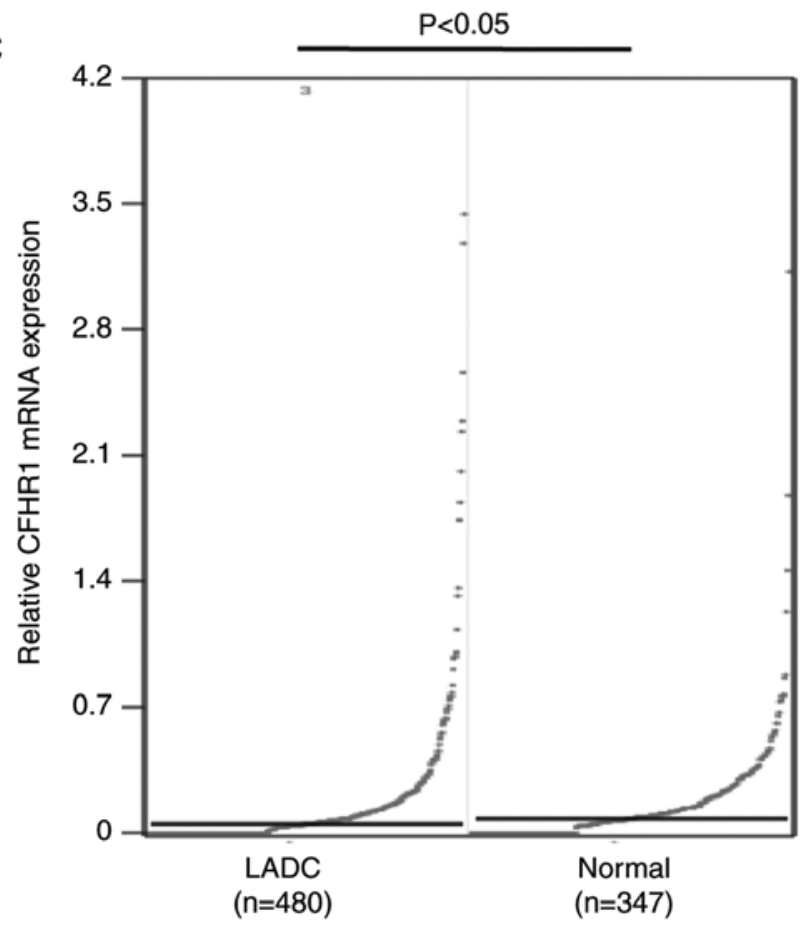

Figure 1. Analysis of CFHRI expression levels in LADC tissues. (A) The expression of CFHRI messenger RNA (mRNA) in Beer Lung and Bhattacharjee Lung was grouped by surrounding normal lung tissues and LADC. (B and C) The mRNA expression of $C F H R 1$ was detected from the UALCAN and GEPIA public databases, respectively. CFHR1, human complement factor H-related protein 1; LADC, lung adenocarcinoma.

performed by two frequently used algorithms, STRING and Cytoscape (Fig. 4A). At the same time, the Pathview database was used to analyze the KEGG pathways (Table SIII), and it was found that the most significant pathway was ribosome (Fig. 4B). Finally, to further illuminate the function among these 243 screened genes, WebGestalt was used to conduct the GO annotations and to identify the main molecular function (protein binding), biological process (response to stimulus and biological regulation) and cellular component (membrane) related to CFHRI biology (Fig. 4C).

\section{Discussion}

The aim of the present study was to understand the potential of human complement factor $\mathrm{H}$-related protein 1 (CFHRI) in the development and treatment of lung adenocarcinoma (LADC). The present study is the first to use multiple public datasets to analyze the expression of CFHRI in LADC tissues. At the same time, the coexpressed genes of $C F H R 1$ were analyzed and several possible signaling pathways were identified that could determine its biological 

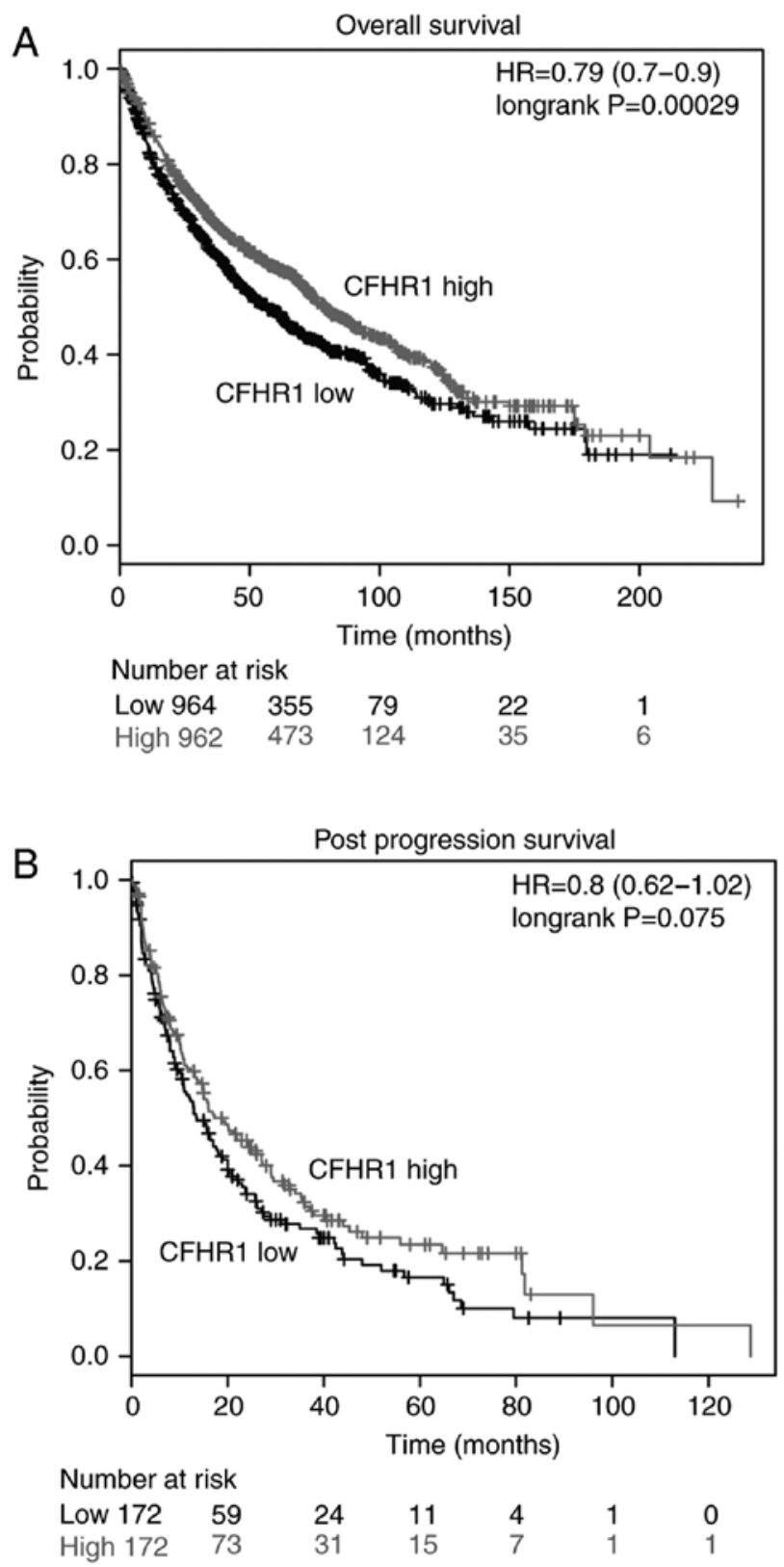

Figure 2. Relationship between $C F H R 1$ expression and the clinical features of patients with LADC. (A) Kaplan-Meier analysis of overall survival (OS) in LADC patients based on CFHRI expression. (B) Kaplan-Meier analysis of post progression survival (PPS) in LADC patients based on CFHRl expression. CFHR1, human complement factor H-related protein 1; LADC, lung adenocarcinoma.

significance in cancer development. Using the Oncomine, UALCAN and GEPIA datasets, it was demonstrated that CFHRI is significantly downregulated in LADC tissues. Moreover, through statistical analysis of clinical data from TCGA, it was found that the expression level of $C F H R 1$ was closely related to KRAS mutation and pathological $\mathrm{T}$ stage in LADC patients.

CFHR1 is a complement modulator that regulates complement by blocking complement $\mathrm{C} 5$ convertase activity and interfering with C5b surface binding (28). In autoimmune atypical hemolytic uremic syndrome (aHUS), CFH is blocked by $\mathrm{FH}$ autoantibodies, and $90 \%$ of patients carry homozygous deletions of CFHRI (29). However, heterozygous CFHRI/CFH
Table I. Single factor clinical data analysis related to CFHRI.

\begin{tabular}{lccc}
\hline Source & No. & Mean \pm SD & P-value \\
\hline Sex & & & 0.350 \\
$\quad$ Male & 207 & $0.959 \pm 1.47$ & \\
Female & 248 & $0.830 \pm 1.46$ & \\
Kras_mutation & & & $\mathbf{0 . 0 1 3}$
\end{tabular}

No

Yes

$34 \quad 1.22 \pm 1.84$

EGFR_mutation

$0.341 \pm 0.427$

No

$\begin{array}{rc}171 & 0.842 \pm 1.18 \\ 64 & 1.09 \pm 1.78\end{array}$

Yes

0.301

EML4_ALK_

translocation

$\begin{array}{lrc}\text { No } & 183 & 0.888 \pm 1.38 \\ \text { Yes } & 23 & 0.978 \pm 1.72 \\ \text { Pathologic_T } & & \\ \text { T1/T1a/T1b } & 140 & 0.979 \pm 1.66 \\ \text { T2/T2a/T2b } & 254 & 0.814 \pm 1.28 \\ \text { T3 } & 41 & 0.603 \pm 0.986 \\ \text { T4 } & 18 & 1.12 \pm 1.47 \\ \text { TX } & 2 & 7.69 \pm 0.868 \\ \text { Race } & & \\ \text { Caucasian } & 355 & 0.907 \pm 1.43 \\ \text { Asian } & 7 & 0.544 \pm 1.01 \\ \text { Black or African- } & 25 & 0.882 \pm 1.63\end{array}$

0.773

American

Pathologic_N

$\begin{array}{lrc}\text { N0 } & 290 & 0.877 \pm 1.48 \\ \text { N1 } & 83 & 0.838 \pm 1.16 \\ \text { N2 } & 70 & 0.990 \pm 1.63 \\ \text { N3 } & 2 & 0 \\ \text { NX } & 9 & 1.22 \pm 2.23\end{array}$

Pathologic_M

M0
MX

$0.886 \pm 1.50$

$0.936 \pm 1.61$

$118 \quad 0.915 \pm 1.38$

Pathologic_stage

Stage I/IA/IB

Stage IIA/IIB

Stage IIIA/IIIB

Stage IV

246
106
79
23

$\begin{array}{rc}246 & 0.908 \pm 1.53 \\ 106 & 0.753 \pm 1.13 \\ 79 & 1.02 \pm 1.63 \\ 23 & 0.895 \pm 1.58\end{array}$

0.002

0.802

0.801

0.560

0.669

0.394

performance score

$\begin{array}{lcc}0-70 & 13 & 0.698 \pm 0.692 \\ 80 & 19 & 1.10 \pm 1.67 \\ 90 & 19 & 0.395 \pm 0.835 \\ 100 & 29 & 0.637 \pm 1.41\end{array}$

Age (years)

$\begin{array}{lrc}40-60 & 116 & 0.858 \pm 1.35 \\ 60-80 & 292 & 0.911 \pm 1.50 \\ >80 & 27 & 0.562 \pm 0.637\end{array}$

0.471

CFHR1, human complement factor H-related protein 1. The clinical characteristics of the patients were downloaded from the dataset (TCGA Provisional) in cBioPortal and have not been published to date. P-values denoted in bold print are significant. 
Table II. Clinical multivariate data related to $C F H R I$.

\begin{tabular}{lccrr}
\hline Source & Type III sum of squares & df & Mean square & F \\
\hline Kras_mutation_found & 4.627 & 1 & 4.627 & 2.513 \\
Pathologic_T & 36.867 & 4 & 9.217 & 0.120 \\
\hline
\end{tabular}

CFHR1, human complement factor H-related protein 1. P-value denoted in bold print is significant.

A

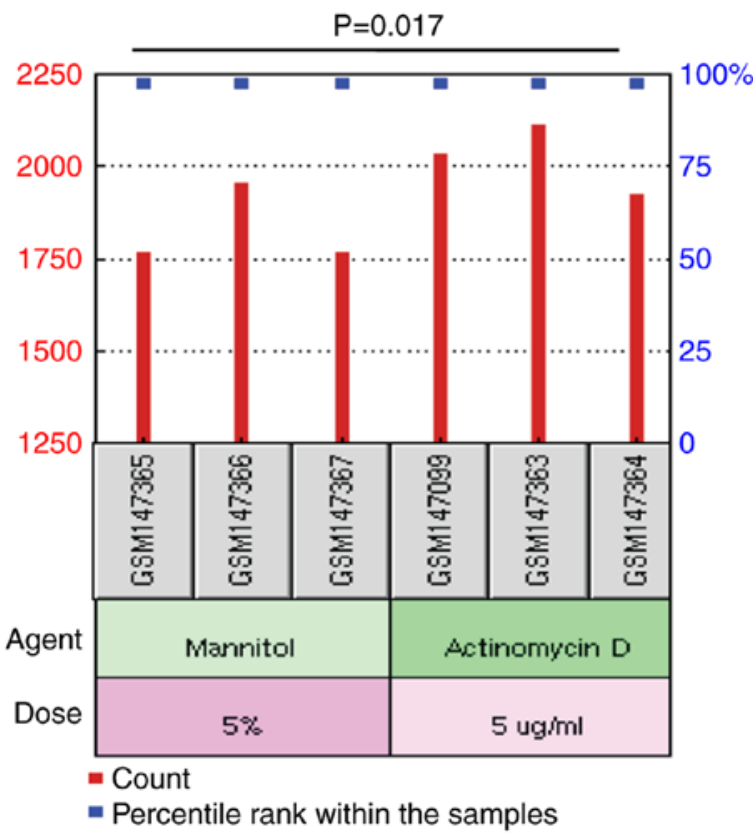

B

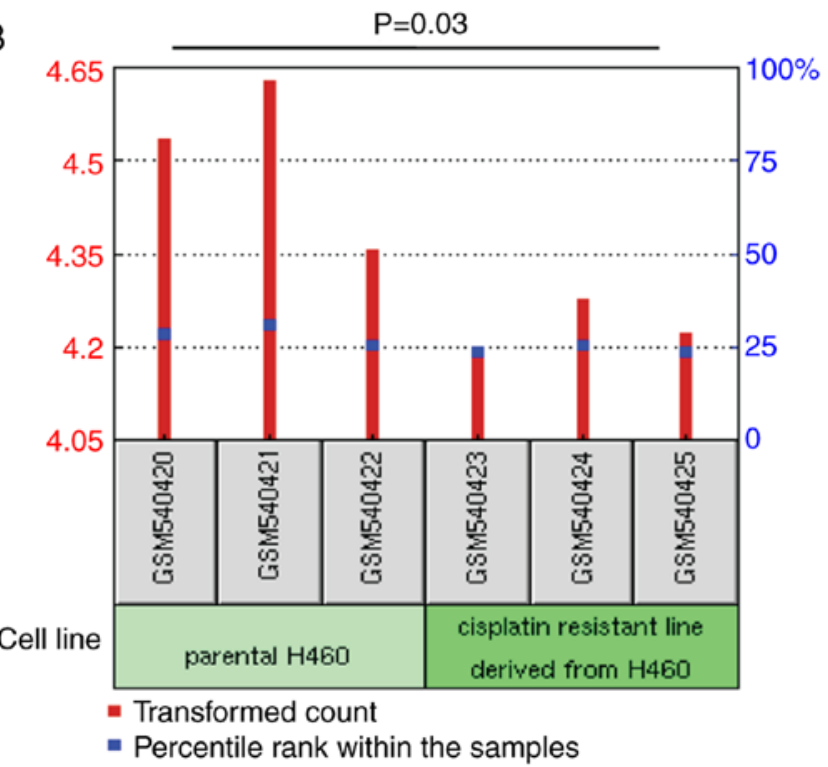

Figure 3. Effect of $C F H R 1$ on the therapeutic response of LADC patients. (A and B) The potential role of CFHRl expression in the treatment of LADC patients was evaluated using two therapeutically relevant microarray datasets (GSE6400 and GSE21656) in the Gene Expression Omnibus (GEO) database. CFHR1, human complement factor H-related protein 1; LADC, lung adenocarcinoma.

hybrid genes were also identified in $4.5 \%$ of patients with aHUS. These genomic rearrangements among $C F H$ and $C F H R$ have been proven to be associated with a high risk of posttransplant recurrence and poor clinical prognosis (30). In addition, Guo et al (31) found that abnormally expressed CFHRl could act as a promising predictive biomarker for cervical squamous cell carcinoma. Using an off-site matrix-based electrochemistry platform, Arya and Estrela further investigated CFHR1 as a bladder cancer protein marker (32). CFHRl gene polymorphisms also showed stronger associations with event-free survival in patients with follicular lymphoma (33). Although several studies have indicated the roles of $C F H R l$ in the pathological process of human diseases, including cancers, no studies have revealed the functions of $C F H R 1$ in LADC. In the present study, we demonstrated that $C F H R 1$ plays a potential role in tumor inhibition in LADC samples. In addition, it was also demonstrated that high expression of $C F H R 1$ is significantly associated with prolonged clinical OS and PPS in LADC patients. This provides an idea for further comprehensive exploration of the molecular mechanism of $C F H R I$ as a promising therapeutic biomarker in LADC.

In the present study, the exact interaction between CFHRI and its coexpressed genes was not found; however, the PPI that was constructed benefits the identification of the function of CFHRI to some extent. Jullien et al (34) discovered that CFHRI is connected with a decreased level of glomerular immune deposits. Moreover, interleukin-6 (IL-6), located in the PPI network (Fig. 4A), is considered as a cytokine that essentially functions in immunoregulation via a signal transducer and activator of transcription 3 (STAT3) -dependent manner (35). Therefore, a phenomenon may exist in which CFHRl controls the secretion of IL-6 to influence the immunoregulation of human cancer cells. In addition, through the functional enrichment annotation analysis, the main functional pathway of the coexpressed genes of $C F H R 1$ has been confirmed to be the ribosome pathway. Previous research has demonstrated that the ribosome signaling pathway is significantly related to the microenvironment and metabolic changes of cancer cells $(36,37)$. However, according to the published literature, no relevant studies have illuminated the detailed function and mechanism of CFHRI in the pathway modulation. Therefore, further studies are needed to clarify the roles of $C F H R 1$ in these KEGG pathways.

Overall, our results suggest that $C F H R 1$ is a candidate tumor suppressor in human LADC disease. The public database-based re-analysis methods also provide a novel research strategy for screening potential biomarkers related to the pathogenesis of malignant human diseases.

\section{Acknowledgements}

Not applicable. 
A

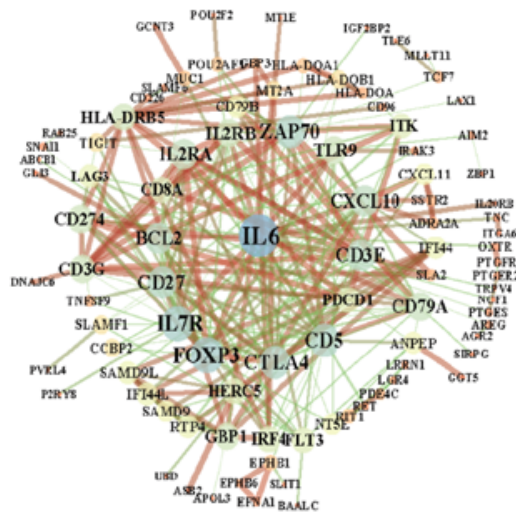

C

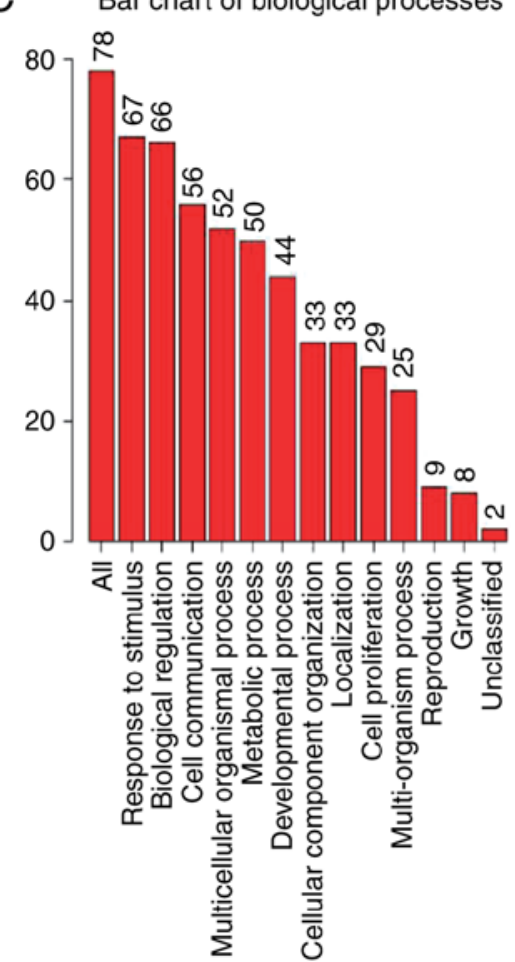

B

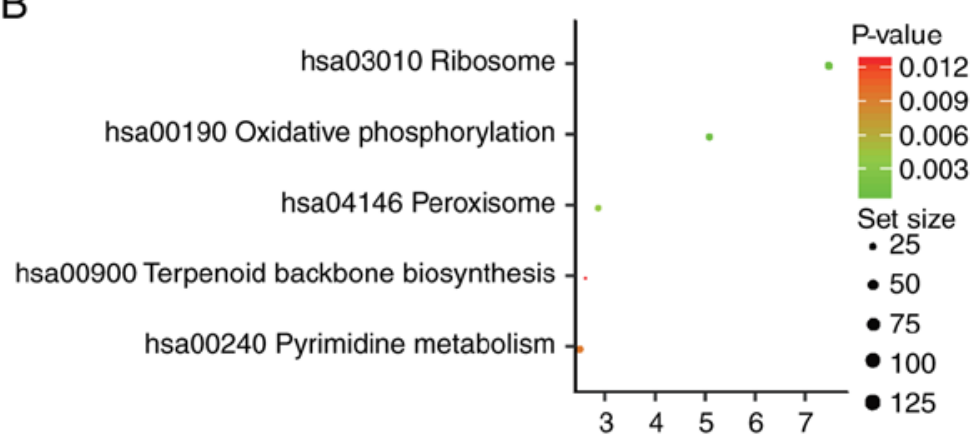

Bar chart of cellular components

Bar chart of molecular functions
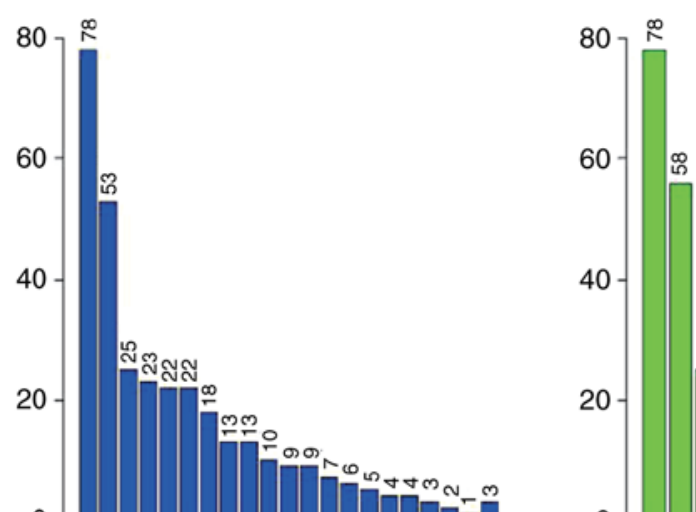

0
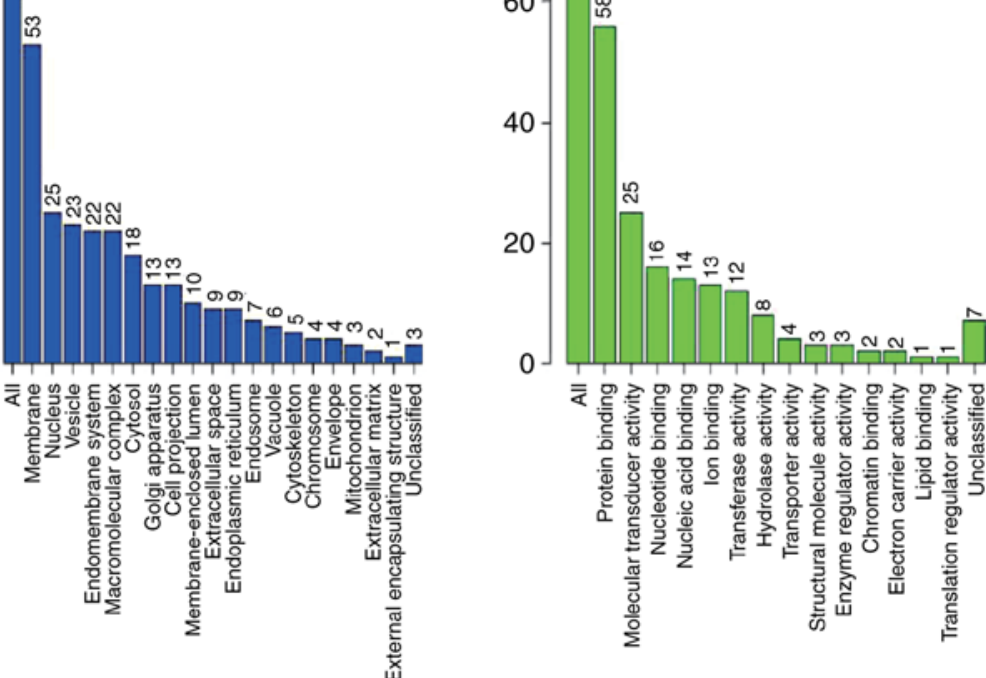

Figure 4. Coexpression network analysis of CFHR1. (A) The PPI network of CFHR1-associated genes, performed by two frequently used algorithms, STRING and Cytoscape. (B) The most significant KEGG pathway, ribosomal, was found in the Pathview database. (C) The main molecular functions, biological processes and cell components related to the biology of $C F H R 1$ were identified by WebGestalt. $C F H R 1$, human complement factor H-related protein 1 ; PPI, protein-protein interaction; KEGG, Kyoto Encyclopedia of Genes and Genomes.

\section{Funding}

The study was supported by the Natural Science Foundation of Hunan Province (grant no. 2019JJ50932), the National Natural Science Foundation of China (grant nos. 81803035, 81703036 and 81572946), the China Postdoctoral Science Foundation (grant no. 2017M610510), the Open-End Fund for the Valuable and Precision Instruments of Central South University (grant no. CSUZC201836), the Youth Fund of Xiangya Hospital (grant no. 2017Q17) and Postdoctoral Science Foundation of Central South University (grant no. 185702).

\section{Availability of data and materials}

All data generated or analyzed during this study are included in this published article.

\section{Authors' contributions}

GW, YY, JZ and ZX concieved and designed the study. GW, XW, $\mathrm{XR}, \mathrm{XC}, \mathrm{SZ}, \mathrm{JW}, \mathrm{LQ}, \mathrm{XY}, \mathrm{CO}, \mathrm{WL}$ and $\mathrm{ZG}$ acquired and interpreted the data. GW, YY, JZ and ZX drafted the manuscript. YY and $\mathrm{ZX}$ revised the manuscript. All authors read and approved the final manuscript, and agree to be accountable for all aspects of the research in ensuring that the accuracy or integrity of any part of the work are appropriately investigated and resolved.

\section{Ethics approval and consent to participate}

Not applicable.

\section{Patient consent for publication}

Not applicable. 


\section{Competing interests}

The authors declare that they have no competing interests.

\section{Author information}

Dr Zhijie Xu is now a Postdoctoral Fellow at the Department of Pharmacy of Xiangya Hospital, Central South University, Changsha, Hunan.

\section{References}

1. Hirsch FR, Scagliotti GV, Mulshine JL, Kwon R, Curran WJ Jr, Wu YL and Paz-Ares L: Lung cancer: Current therapies and new targeted treatments. Lancet 389: 299-311, 2017.

2. Wei J, Yan Y, Chen X, Qian L, Zeng S, Li Z, Dai S, Gong Z and Xu Z: The roles of plant-derived Triptolide on non-small cell lung cancer. Oncol Res 27: 849-858, 2019.

3. Ulahannan D, Khalifa J, Faivre-Finn C and Lee SM: Emerging treatment paradigms for brain metastasis in non-small-cell lung cancer: An overview of the current landscape and challenges ahead. Ann Oncol 28: 2923-2931, 2017.

4. Zhou S, Yan Y, Chen X, Wang X, Zeng S, Qian L, Wei J, Yang X, Zhou Y, Gong Z and Xu Z: Roles of highly expressed PAICS in lung adenocarcinoma. Gene 692: 1-8, 2019

5. Zhang R, Sun S, Ji F, Liu C, Lin H, Xie L, Yang H, Tang W, Zhou Y, Xu J and Li P: CNTN-1 enhances chemoresistance in human lung adenocarcinoma through induction of epithelial-mesenchymal transition by targeting the PI3K/Akt pathway. Cell Physiol Biochem 43: 465-480, 2017.

6. Yan Y, Su W, Zeng S, Qian L, Chen X, Wei J, Chen N, Gong Z and $\mathrm{Xu} \mathrm{Z}$ : Effect and mechanism of tanshinone $\mathrm{i}$ on the radiosensitivity of lung cancer cells. Mol Pharm 15: 4843-4853, 2018

7. Skerka C, Chen Q, Fremeaux-Bacchi V and Roumenina LT: Complement factor $\mathrm{H}$ related proteins (CFHRs). Mol Immunol 56: 170-180, 2013

8. Rogers LM, Mott SL, Smith BJ,Link BK, Sahin D and Weiner GJ: Complement-regulatory proteins CFHR 1 and CFHR3 and patient response to anti-CD20 monoclonal antibody therapy. Clin Cancer Res 23: 954-961, 2017.

9. Hageman GS, Hancox LS, Taiber AJ, Gehrs KM, Anderson DH, Johnson LV, Radeke MJ, Kavanagh D, Richards A, Atkinson $\mathrm{J}$, et al: Extended haplotypes in the complement factor $\mathrm{H}(\mathrm{CFH})$ and $\mathrm{CFH}$-related (CFHR) family of genes protect against age-related macular degeneration: Characterization, ethnic distribution and evolutionary implications. Ann Med 38: 592-604, 2006

10. Jullien P, Laurent B, Claisse G, Masson I, Dinic M, Thibaudin D, Berthoux F, Alamartine E, Mariat C and Maillard N: Deletion Variants of CFHR1 and CFHR3 associate with mesangial immune deposits but not with progression of $\operatorname{IgA}$ nephropathy. J Am Soc Nephrol 29: 661-669,2018.

11. Fratelli M,Bolis M, Kurosaki M, Dori M, Guarnaccia V, Spinelli O, Alberti M, Valoti E, Pileggi S, Noris M, et al: Association of CFHR1 homozygous deletion with acute myelogenous leukemia in the European population. Leuk Lymphoma 57: 1234-1237, 2016.

12. Cui L, Fu J, Pang JC, Qiu ZK, Liu XM, Chen FR, Shi HL, Ng HK and Chen ZP: Overexpression of IL-7 enhances cisplatin resistance in glioma. Cancer Biol Ther 13: 496-503, 2012.

13. Rhodes DR, Kalyana-Sundaram S, Mahavisno V, Varambally R Yu J, Briggs BB, Barrette TR, Anstet MJ, Kincead-Beal C, Kulkarni P, et al: Oncomine 3.0: Genes, pathways and networks in a collection of 18,000 cancer gene expression profiles. Neoplasia 9: 166-180, 2007.

14. Chandrashekar DS, Bashel B, Balasubramanya SAH, Creighton CJ, Ponce-Rodriguez I, Chakravarthi BVSK and Varambally S: UALCAN: A portal for facilitating tumor subgroup gene expression and survival analyses. Neoplasia 19: 649-658, 2017.

15. Tang Z, Li C, Kang B, Gao G, Li C and Zhang Z: GEPIA: A web server for cancer and normal gene expression profiling and interactive analyses. Nucleic Acids Res 45: W98-W102, 2017

16. Lánczky A, Nagy Á, Bottai G, Munkácsy G, Szabó A, Santarpia L and Győrffy B: miRpower: A web-tool to validate survival-associated miRNAs utilizing expression data from 2178 breast cancer patients. Breast Cancer Res Treat 160: 439-446, 2016

17. Yan Y, Xu Z, Hu X, Qian L, Li Z, Zhou Y, Dai S, Zeng S and Gong Z: SNCA is a functionally low-expressed gene in lung adenocarcinoma. Genes (Basel) 9: E16, 2018.
18. Wang Z, Lecane PS, Thiemann P, Fan Q, Cortez C, Ma X, Tonev D, Miles D, Naumovski L, Miller RA, et al: Synthesis and biologic properties of hydrophilic sapphyrins, a new class of tumor-selective inhibitors of gene expression. Mol Cancer 6: 9, 2007.

19. Sun Y, Zheng S, Torossian A, Speirs CK, Schleicher S, Giacalone NJ, Carbone DP, Zhao Z and Lu B: Role of insulin-like growth factor-1 signaling pathway in cisplatin-resistant lung cancer cells. Int J Radiat Oncol Biol Phys 82: e563-e572, 2012.

20. Gao J, Aksoy BA, Dogrusoz U, Dresdner G, Gross B, Sumer SO, Sun Y, Jacobsen A, Sinha R, Larsson E, et al: Integrative analysis of complex cancer genomics and clinical profiles using the cBioPortal. Sci Signal 6: pl1, 2013.

21. Szklarczyk D, Morris JH, Cook H, Kuhn M, Wyder S, Simonovic M, Santos A, Doncheva NT, Roth A, Bork P, et al: The STRING database in 2017: Quality-controlled protein-protein association networks, made broadly accessible. Nucleic Acids Res 45: D362-D368, 2017.

22. Su G, Morris JH, Demchak B and Bader GD: Biological network exploration with Cytoscape 3. Curr Protoc Bioinformatics 47: 8.13.1-24, 2014

23. Wang J, Vasaikar S, Shi Z, Greer M and Zhang B: WebGestalt 2017: A more comprehensive, powerful, flexible and interactive gene set enrichment analysis toolkit. Nucleic Acids Res 45: W130-W137, 2017.

24. Luo W, Pant G, Bhavnasi YK, Blanchard SG Jr and Brouwer C Pathview Web: User friendly pathway visualization and data integration. Nucleic Acids Res 45: W501-W508, 2017.

25. Bhattacharjee A, Richards WG, Staunton J, Li C, Monti S, Vasa P, Ladd C, Beheshti J, Bueno R, Gillette M, et al: Classification of human lung carcinomas by mRNA expression profiling reveals distinct adenocarcinoma subclasses. Proc Natl Acad Sci USA 98: 13790-13795, 2001.

26. Beer DG, Kardia SL, Huang CC, Giordano TJ, Levin AM, Misek DE, Lin L, Chen G, Gharib TG, Thomas DG, et al: Gene-expression profiles predict survival of patients with lung adenocarcinoma. Nat Med 8: 816-824, 2002.

27. Zhou H, Vallieres M, Bai HX, Su C, Tang H, Oldridge D, Zhang Z, Xiao B, Liao W, Tao Y, et al: MRI features predict survival and molecular markers in diffuse lower-grade gliomas. Neuro Oncol 19: 862-870, 2017.

28. Hannan JP, Laskowski J, Thurman JM, Hageman GS and Holers VM: Mapping the complement factor H-related protein 1 (CFHR1):C3b/C3d interactions. PLoS One 11: e0166200, 2016.

29. Trojnar E, Józsi M, Uray K, Csuka D, Szilágyi Á, Milosevic D, Stojanović VD, Spasojević B, Rusai K, Müller T, et al: Analysis of linear antibody epitopes on factor $\mathrm{H}$ and CFHR1 using sera of patients with autoimmune atypical hemolytic uremic syndrome. Front Immunol 8: 302, 2017.

30. Valoti E, Alberti M, Tortajada A, Garcia-Fernandez J, Gastoldi S, Besso L, Bresin E, Remuzzi G, Rodriguez de Cordoba S and Noris M: A novel atypical hemolytic uremic syndrome-associated hybrid CFHR1/CFH gene encoding a fusion protein that antagonizes factor $\mathrm{H}$-dependent complement regulation. J Am Soc Nephrol 26: 209-219, 2015.

31. Guo X, Hao Y, Kamilijiang M, Hasimu A, Yuan J, Wu G, Reyimu H, Kadeer N and Abudula A: Potential predictive plasma biomarkers for cervical cancer by 2D-DIGE proteomics and ingenuity pathway analysis. Tumour Biol 36: 1711-1720, 2015.

32. Arya SK and Estrela P: Electrochemical ELISA-based platform for bladder cancer protein biomarker detection in urine. Biosens Bioelectron 117: 620-627, 2018.

33. Charbonneau B, Maurer MJ, Fredericksen ZS, Zent CS, Link BK, Novak AJ, Ansell SM, Weiner GJ, Wang AH, Witzig TE, et al: Germline variation in complement genes and event-free survival in follicular and diffuse large B-cell lymphoma. Am J Hematol 87: 880-885, 2012.

34. Jullien P, Laurent B, Claisse G, Masson I, Dinic M, Thibaudin D, Berthoux F, Alamartine E, Mariat C and Maillard N: Deletion variants of CFHR1 and CFHR3 associate with mesangial immune deposits but not with progression of $\operatorname{Ig} \mathrm{A}$ nephropathy. $\mathrm{J}$ Am Soc Nephrol 29: 661-669, 2018.

35. Lamano JB, Lamano JB, Li YD, DiDomenico JD, Choy W, Veliceasa D, Oyon DE, Fakurnejad S, Ampie L, Kesavabhotla $\mathrm{K}$, et al: Glioblastoma-derived IL6 induces immunosuppressive peripheral myeloid cell PD-L1 and promotes tumor growth. Clin Cancer Res 25: 3643-3657, 2019.

36. Bustelo XR and Dosil M: Ribosome biogenesis and cancer: basic and translational challenges. Curr Opin Genet Dev 48: 22-29, 2018.

37. de la Cruz J, Gómez-Herreros F, Rodríguez-Galán O, Begley V, de la Cruz Muñoz-Centeno M and Chávez S: Feedback regulation of ribosome assembly. Curr Genet 64: 393-404, 2018

This work is licensed under a Creative Commons Attribution-NonCommercial-NoDerivatives 4.0 International (CC BY-NC-ND 4.0) License. 